\title{
Practice guideline: Cervical and ocular vestibular evoked myogenic potential testing
}

Report of the Guideline Development, Dissemination, and Implementation Subcommittee of the American Academy of Neurology

Terry D. Fife, MD

James G. Colebatch, MB, DSc

Kevin A. Kerber, MD

Krister Brantberg, MD

Michael Strupp, MD

Hyung Lee, MD

Mark F. Walker, MD

Eric Ashman, MD

Jeffrey Fletcher, MD

Brian Callaghan, MD

David S. Gloss II, MD, MPH\&TM

Correspondence to

American Academy of Neurology: guidelines@aan.com

Supplemental data at Neurology.org

\section{ABSTRACT}

Objective: To systematically review the evidence and make recommendations with regard to diagnostic utility of cervical and ocular vestibular evoked myogenic potentials (cVEMP and oVEMP, respectively). Four questions were asked: Does cVEMP accurately identify superior canal dehiscence syndrome (SCDS)? Does oVEMP accurately identify SCDS? For suspected vestibular symptoms, does cVEMP/oVEMP accurately identify vestibular dysfunction related to the saccule/utricle? For vestibular symptoms, does cVEMP/oVEMP accurately and substantively aid diagnosis of any specific vestibular disorder besides SCDS?

Methods: The guideline panel identified and classified relevant published studies (January 1980December 2016) according to the 2004 American Academy of Neurology process.

Results and Recommendations: Level C positive: Clinicians may use cVEMP stimulus threshold values to distinguish SCDS from controls (2 Class III studies) (sensitivity 86\%-91\%, specificity 90\%-96\%). Corrected cVEMP amplitude may be used to distinguish SCDS from controls (2 Class III studies) (sensitivity 100\%, specificity 93\%). Clinicians may use oVEMP amplitude to distinguish SCDS from normal controls (3 Class III studies) (sensitivity $77 \%-100 \%$, specificity 98\%-100\%). oVEMP threshold may be used to aid in distinguishing SCDS from controls (3 Class III studies) (sensitivity 70\%-100\%, specificity 77\%-100\%). Level U: Evidence is insufficient to determine whether CVEMP and OVEMP can accurately identify vestibular function specifically related to the saccule/utricle, or whether cVEMP or oVEMP is useful in diagnosing vestibular neuritis or Ménière disease. Level $C$ negative: It has not been demonstrated that CVEMP substantively aids in diagnosing benign paroxysmal positional vertigo, or that cVEMP or oVEMP aids in diagnosing/managing vestibular migraine. Neurology ${ }^{\circledR}$ 2017;89:2288-2296

\section{GLOSSARY}

AAN = American Academy of Neurology; $\mathbf{B P P V}=$ benign paroxysmal positional vertigo; $\mathbf{C l}=$ confidence interval; $\mathbf{c V E M P}=$ cervical vestibular evoked myogenic potential; $\mathbf{n H L}=$ normal hearing level; oVEMP = ocular vestibular evoked myogenic potential; SCDS = superior canal dehiscence syndrome; VEMP = vestibular evoked myogenic potential; VM = vestibular migraine; $\mathbf{V N}=$ vestibular neuritis.
Vestibular evoked myogenic potential (VEMP) testing averages short latency myogenic responses evoked by sound that stimulates activation of the saccule or utricle, or both. ${ }^{1,2}$ The US Food and Drug Administration approved VEMP in October 2015. Caloric testing assesses only horizontal semicircular canal vestibulo-ocular reflex function, and the video head impulse test assesses function of all 6 semicircular canals, whereas VEMP testing appears to assess function of only the saccule/utricle. ${ }^{3-6}$
Types of VEMP testing. There are 2 types of VEMP testing: cervical VEMP (cVEMP) and ocular VEMP (oVEMP).

The cVEMP test is believed to assess saccular vestibular signals carried via the vestibulospinal tract. ${ }^{7}$ cVEMP is performed by applying sound stimulation to 1 ear while recording surface EMG over the ipsilateral sternocleidomastoid muscle (figure 1). Soundresponsive vestibular cells, mainly within the inner ear saccule, momentarily inhibit ipsilateral muscle tone
From the Department of Neurology (T.D.F.), Barrow Neurological Institute and University of Arizona College of Medicine, Phoenix; Department of Neurology (J.G.C.), Prince of Wales Hospital, Clinical School, University of New South Wales and Neuroscience Research Australia, Randwick, Sydney; Departments of Neurology (K.A.K., B.C.) and Neurosurgery (J.F.), University of Michigan, Ann Arbor; Department of Audiology and Neurotology (K.B.), Karolinska University Hospital, Stockholm, Sweden; Department of Neurology and German Center for Dizziness and Balance Disorders (M.S.), University of Munich, Germany; Department of Neurology (H.L.), Keimyung University School of Medicine, Daegu, South Korea; Department of Neurology (M.F.W.), Case Western Reserve University, and Louis Stokes Cleveland Veterans Affairs Medical Center, OH; Bronson Neuroscience Center (E.A.), Kalamazoo, MI; and Department of Neurology (D.S.G.), Charleston Area Medical Center, WV.

Approved by the Guideline Development, Dissemination, and Implementation Subcommittee on January 21, 2017; by the Practice Committee on April 10, 2017; and by the AAN Institute Board of Directors on September 5, 2017.

Go to Neurology.org for full disclosures. Funding information and disclosures deemed relevant by the authors, if any, are provided at the end of the article. 
Figure 1 Electrode placement montage for cervical vestibular evoked myogenic potential of the right ear

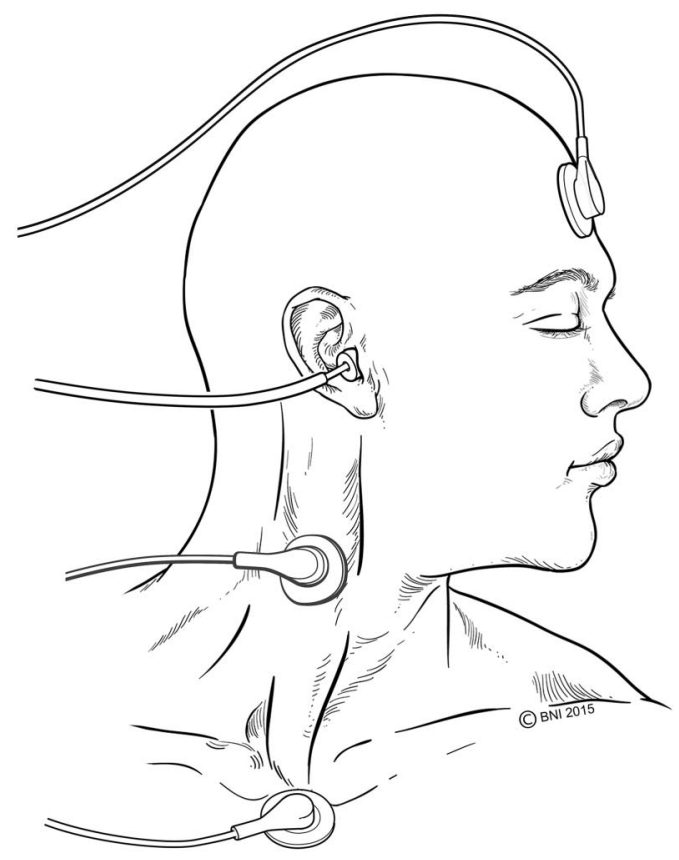

Surface recording electrodes are placed on the tonically contracted right sternocleidomastoid (achieved by having the patient actively turn the head to the left and lift the head slightly) during recordings. () Barrow Neurological Institute, Phoenix, AZ. Used with permission.

via the cervical vestibulocollic pathway (figure 2). ${ }^{8-10}$ Surface EMG responses from the tonically contracted ipsilateral sternocleidomastoid muscle are averaged to yield a biphasic waveform response (figure 3). cVEMP responses can also be derived from the masseter, triceps, and gastrocnemius muscles. ${ }^{11,12}$

The oVEMP test is believed to measure vestibular function from the utricle via the superior vestibular nerve, which then crosses the midline to the contralateral medial longitudinal fasciculus and the oculomotor nucleus (figure 4). ${ }^{9,13}$ oVEMP does not substantially involve the semicircular canals. ${ }^{14}$ oVEMP uses an air- or bone-conducted sound stimulus and averages the surface EMG responses from the contralateral inferior oblique muscle (figure 4) to yield a biphasic waveform (figure 5). Measurements are made of the latencies of the early peaks ( $\mathrm{n} 10$ or $\mathrm{n} 1$ and p16 or p2 for oVEMP) and a peak-to-peak amplitude (figure 5).

Technical considerations in VEMP. cVEMP technical standards have been proposed. ${ }^{15}$ VEMP responses attenuate after age 60 years, and thus the studies included here apply to people aged $<60$ years. ${ }^{16,17}$ Sensorineural hearing loss does not affect cVEMP/ oVEMP. ${ }^{18}$ Conductive hearing loss may reduce sound intensity at the oval window and render
VEMP responses unobtainable. For both cVEMP and oVEMP, the minimum sound stimulus needed to evoke a biphasic VEMP response is called the threshold (table e-1 at Neurology.org).

This guideline addresses published evidence related to cVEMP and oVEMP for peripheral vestibular disorders.

Superior canal dehiscence syndrome. Superior canal dehiscence syndrome (SCDS) is caused by an abnormal opening (dehiscence) in the temporal bone that forms the roof of the superior semicircular canal. ${ }^{19}$ Overall, $1 \%-2 \%$ of the population has abnormal thinning of the temporal bone near the superior semicircular canal. ${ }^{20}$ Further erosion may occur with age. ${ }^{21}$ The average age at diagnosis is 46 years. ${ }^{22}$ Dehiscence renders the membranous labyrinth unusually susceptible to sound and pressure changes.

SCDS diagnosis is based on the combination of vestibular and auditory signs and symptoms and temporal bone CT. Patients with SCDS commonly report pressure-induced (coughing, sneezing, straining) and sound-induced vertigo, dizziness, and the Tullio phenomenon (dizziness induced by sound) or autophony (hearing one's internal body sounds) due to increased sensitivity to sound conducted through bone. Clinical examination may reveal eye movements induced by Valsalva maneuvers, by pressure in the external auditory canal, or by sounds. ${ }^{19,23}$ Patients may have an air-bone gap, especially at the lower frequencies. ${ }^{24}$ For those with disabling symptoms, case series suggest a benefit with surgical plugging or resurfacing of the bony opening. ${ }^{25}$

A 2000 American Academy of Neurology (AAN) guideline provides guidance on vestibular testing techniques in adults and children. ${ }^{26}$ In this new guideline, 4 questions were asked regarding the diagnostic accuracy of cVEMP and oVEMP: (1) Does cVEMP accurately identify SCDS? (2) Does oVEMP accurately identify SCDS? (3) For suspected vestibular symptoms, does cVEMP/oVEMP accurately identify vestibular dysfunction related to the saccule/ utricle? (4) For vestibular symptoms, does cVEMP/ oVEMP accurately and substantively aid in diagnosis of any specific vestibular disorder besides SCDS?

DESCRIPTION OF THE ANALYTIC PROCESS In September 2010, the AAN guideline subcommittee convened an expert panel to develop this practice guideline (appendices e- 1 and e-2), following the process described in the 2004 AAN process manual. ${ }^{27}$ The panel searched MEDLINE, Cochrane Central Register of Controlled Trials (CENTRAL), Literatura Latino Americana em Ciências da Saúde (LILACS), and Science Citation Index for relevant articles in all languages published from January 1, 1980, through March 1, 2015, finding only relevant articles in 
Figure 2 The predominant reflex pathway mediating cervical vestibular evoked myogenic potential responses

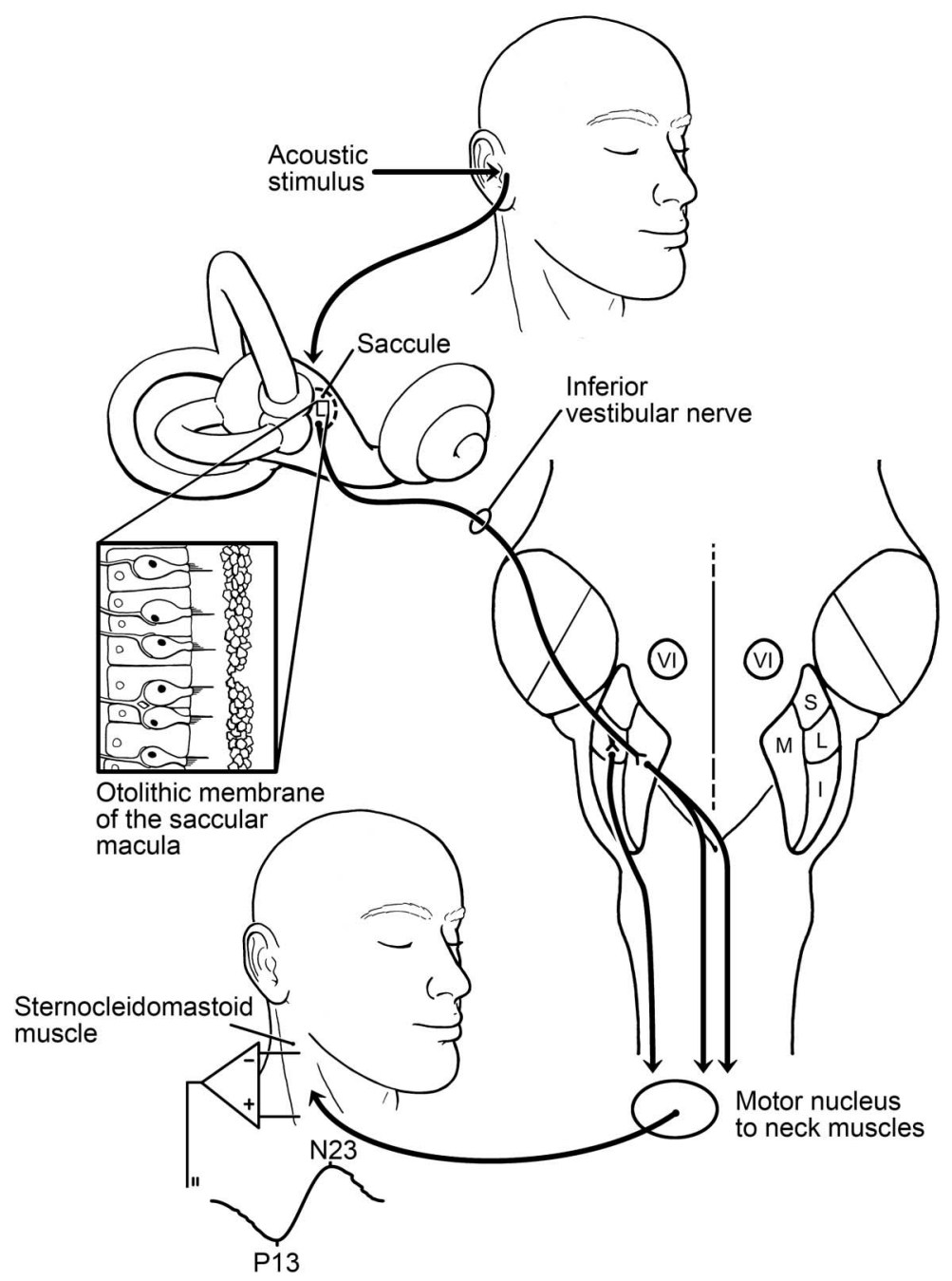

Sound stimulates the saccule, which carries the signal through the ipsilateral inferior vestibular nerve to the vestibular nucleus from which vestibulospinal (vestibulocollic) pathway transmits a momentary inhibitory signal to the spinal accessory nerve supplying the ipsilateral sternocleidomastoid muscle. The momentary inhibitory responses are averaged as evoked potentials. $I$ = inferior vestibular nucleus; $L=$ lateral vestibular nucleus; $M=$ medial vestibular nucleus; $\mathrm{S}=$ superior vestibular nucleus; $\mathrm{VI}=$ abducens nucleus. (C) Barrow Neurological Institute, Phoenix, AZ. Used with permission.

English. A search update (November 2016) sought articles published March 1, 2015, through November 1, 2016. Included studies examined utility of VEMP in diagnosis, including case control, cohort, case series $(n>6)$, or meta-analyses. Studies were excluded if they were not relevant to VEMP or vestibular disorders, or were not peer reviewed. Key words were "click evoked myogenic," "vestibular evoked myogenic," and "VEMP."

The search yielded 2,536 articles, whose titles and abstracts were reviewed for relevance by at least 2 panel members. Of those articles, 257 underwent full-text review for inclusion by at least 2 panelists (including an AAN evidence-based medicine methodologist), who identified 97 articles as relevant and rated them according to the 2004 AAN diagnostic accuracy scheme for classification of risk of bias (appendix e-3). A third panelist adjudicated disagreements in ratings. The panel then narrowed the guideline focus to exclude VEMP use in disorders affecting vestibulospinal spinal cord conduction, and thus discarded 39 articles on this topic, leaving 58 remaining articles that were rated. Because no articles attained a Class I or II rating, only Class III studies were included. Recommendation levels were tied directly to the evidence (appendix e-4). Tables e-2 through e-4 describe how vestibular diagnoses were determined in the rated articles.

ANALYSIS OF EVIDENCE Does cVEMP accurately identify patients with SCDS? There were 9 Class III studies. ${ }^{24,25,28-34}$ A meta-analysis was considered but not performed given the heterogeneity of the studies.

cVEMP threshold. There were 2 positive Class III studies $^{24,25}$ and another Class III study downgraded for the question of threshold due to incorporation bias. $^{28}$

The first study was a retrospective cohort of 65 patients. $^{24}$ At the $500-\mathrm{Hz}$ tone bursts, VEMP thresholds were $66 \mathrm{~dB}$ (95\% confidence interval [CI] 62.1-67.0 dB) for SCDS ears and $85 \mathrm{~dB}$ (95\% CI 82.6-87.4 dB) for non-SCDS ears. The cVEMP using a threshold of $\leq 65 \mathrm{~dB}$ normal hearing level (nHL) yielded $91.4 \%$ sensitivity and 95.8\% specificity.

The second study (case control) examined the cVEMP threshold values of 29 patients with suspected SCDS and 50 healthy control ears. ${ }^{25}$ The best combination of sensitivity and specificity was found using cVEMP threshold of $\leq 85 \mathrm{~dB}$ nHL, which yielded $86 \%$ sensitivity (95\% CI 66\%-95\%) and $90 \%$ specificity (95\% CI 77\%-96\%) in separating patients with SCDS from controls.

cVEMP amplitude. Two negative underpowered Class III studies ${ }^{30,31}$ showed that cVEMP raw amplitude possibly did not effectively detect SCDS.

The first study of 67 patients compared 17 CTdemonstrated SCDS ears with 107 CTdemonstrated non-SCDS ears. ${ }^{30}$ After a Bonferroni correction, no significant differences were found.

The second study used a striker to enhance cVEMP responses and included 5 patients with SCDS and 20 normal controls. ${ }^{31}$ The mean amplitudes were $53.3 \mu \mathrm{V}$ (95\% CI 29.9-76.8 $\mu \mathrm{V}$ ) for controls and $63.1 \mu \mathrm{V}$ (95\% CI 52.0-74.4 $\mu \mathrm{V}$ ) for those with SCDS, but there was too much overlap to separate SCDS ears from controls.

Corrected cVEMP amplitude. There were 5 Class III studies that addressed corrected VEMP amplitudes. ${ }^{28,29,32-34}$ For air-conducted cVEMP amplitudes, lower stimulus intensity may be more effective 
Figure 3 Cervical vestibular evoked myogenic potential (cVEMP) waveform in a healthy individual

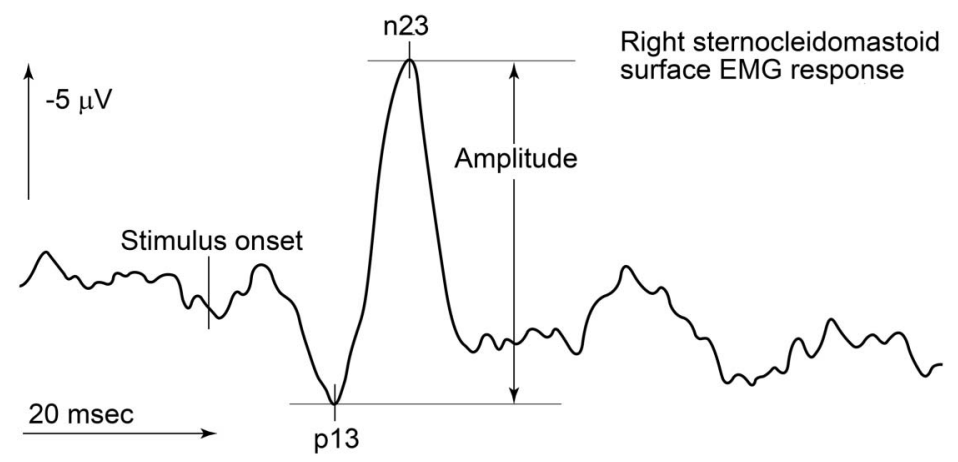

The recordings are from the right sternocleidomastoid muscle in response to $500-\mathrm{Hz}$ tone bursts ( 2 ms duration, $2 \mathrm{~ms}$ rise/fall), with an intensity of $130 \mathrm{~dB}$ pSPL. The waveform shows the positive-negative cVEMP (p13-n23) on the side to which the sound stimulation is applied. Measurements include the latency, the amplitude, and the threshold (least intense sound stimulus to still yield a reliable response). The responses occur only on the side of the sound stimulation. Some laboratories display an inverted waveform with the positive wave up instead of the negative wave up. ( ) Barrow Neurological Institute, Phoenix, AZ. Used with permission. amplitude cutoff of $2.5 \mathrm{SD}$ above the controls mean, cVEMP had a sensitivity of $100 \%(13 / 13)$ and specificity of $93 \%(14 / 15)$ in distinguishing patients with SCDS from controls.

Conclusions. cVEMP threshold values possibly distinguish patients with SCDS from controls (2 Class III studies) with sensitivity of $86 \%-91 \%$ and specificity of $90 \%-96 \%$. Corrected cVEMP amplitude possibly distinguishes patients with SCDS from controls (2 Class III and 3 underpowered Class III studies) with sensitivity of $100 \%$ and specificity of $93 \%$. Raw cVEMP amplitude values possibly do not distinguish patients with SCDS from controls (2 underpowered Class III studies).

Recommendations. Clinicians may use cVEMP threshold values to distinguish patients with SCDS from controls (Level C). Corrected cVEMP amplitude may also be used to distinguish patients with SCDS from controls (Level C).

Does oVEMP accurately identify patients with SCDS? Seven Class III studies were identified. ${ }^{25,28,29,31,35-37}$

oVEMP amplitude. One retrospective study looked at 9 patients with SCDS matched to controls. ${ }^{35}$ Mean raw amplitudes were greater in SCDS ears, $2.68 \mu \mathrm{V}$ (95\% CI 2.46-2.90 $\mu \mathrm{V})$, than in controls, $0.93 \mu \mathrm{V}$ (95\% CI 0.91-0.95 $\mu \mathrm{V})$. Using an $\mathrm{n} 10$ amplitude of $\geq 1.5 \mu \mathrm{V}$, oVEMP had $100 \%$ sensitivity and $100 \%$ specificity in differentiating patients with SCDS from controls.

A second study ${ }^{28}$ compared SCDS ears with normal ears. The mean amplitude of patients with SCDS was significantly higher, $35.9 \mu \mathrm{V}(95 \% \mathrm{CI} 26.7-45.1$ $\mu \mathrm{V})$, than controls, $8.9 \mu \mathrm{V}(95 \%$ CI 6.24-11.56 $\mu \mathrm{V})$. With use of a stimulus intensity of $105 \mathrm{~dB}$ pSPL and corrected amplitude of $>2.5 \mathrm{SD}$ above the mean of normal controls, oVEMP amplitudes had a 77\% (10/13) sensitivity and $100 \%$ (15/15) specificity in distinguishing SCDS ears from normal ears.

A third study examined the oVEMP n10 amplitude of 29 ears in patients with suspected SCDS compared with 50 control ears. ${ }^{25}$ Use of an $n 10$ amplitude of $\geq 9.3 \mu \mathrm{V}$ as the cutoff yielded a sensitivity of $100 \%(95 \%$ CI $88 \%-100 \%)$ and specificity of $100 \%$ (95\% CI 93\%-100\%). Using an oVEMP peak-to-peak amplitude of $>17.1 \mu \mathrm{V}$ as the cutoff resulted in 100\% sensitivity (95\% CI 85\%-100\%) and $98 \%$ specificity (95\% CI 89\%-100\%).

A fourth study, described previously, compared oVEMP n10 amplitudes using 4 different stimuli. ${ }^{29}$ Use of an n10 amplitude of $\geq 8.25 \mu \mathrm{V}$ as the cutoff yielded a sensitivity of $100 \%$ (95\% CI 72\%-100\%) and a specificity of $100 \%(95 \%$ CI $72 \%-100 \%)$.

In a fifth study comparing SCDS ears with normal ears, ${ }^{31}$ controls had a mean of $12.31 \mu \mathrm{V}(95 \% \mathrm{CI}$ 10.9-13.7 $\mu \mathrm{V}$ ). SCDS-affected ears had a mean of 


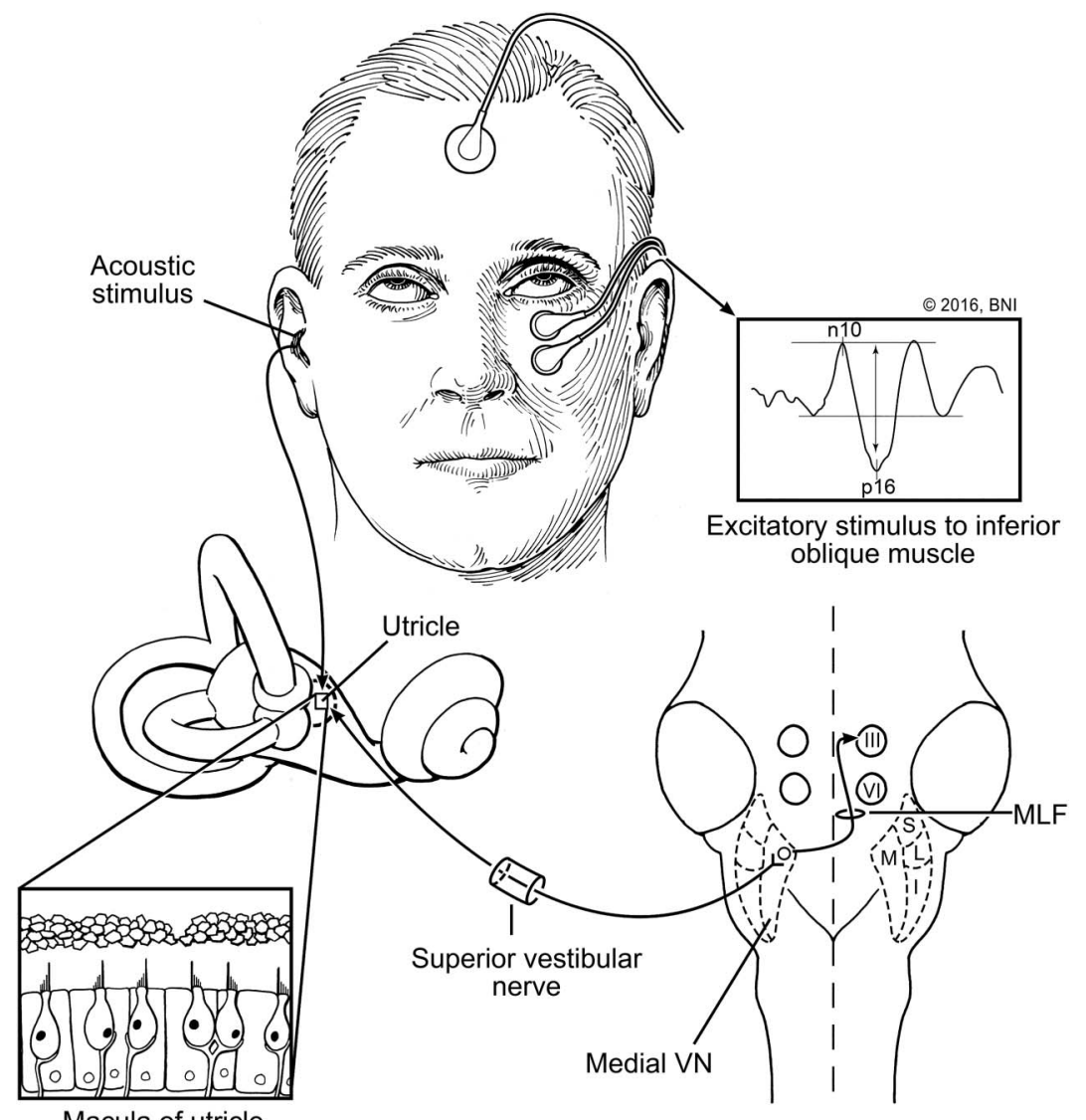

Sound stimulates the utricle, which carries the signal through the ipsilateral superior vestibular nerve to the ipsilateral vestibular nucleus. The utriculo-ocular signals cross the midline and travel up the medial longitudinal fasciculus to send an excitatory stimulus to the inferior oblique subnucleus of the oculomotor nucleus, causing momentary contraction which is averaged repetitively. I = inferior vestibular nucleus; III = oculomotor nucleus; $L$ = lateral vestibular nucleus; $M=$ medial vestibular nucleus; $\mathrm{MLF}=$ medial longitudinal fasciculus; $\mathrm{S}=$ superior vestibular nucleus; $\mathrm{VI}=$ abducens nucleus; $\mathrm{VN}=$ vestibular nucleus. () Barrow Neurological Institute, Phoenix, AZ. Used with permission.

12.14 $\mu \mathrm{V}$, but no information was given about SDs, and sensitivity and specificity could not be determined.

oVEMP evoked by stimulus 4,000-Hz tone burst at the midline forehead. One study, aiming to find a single method to distinguish SCDS ears from normal ears, compared 30 SCDS ears with 44 control ears ${ }^{36}$ after application of a $4,000-\mathrm{Hz}$ sound stimulus to the midline forehead. All SCDS ears had an oVEMP response, and none of the 44 healthy ears had an oVEMP response, yielding $100 \%$ sensitivity and $100 \%$ specificity.

oVEMP threshold. Two studies supported use of oVEMP stimulus threshold. ${ }^{28,37}$

The first study, comparing 10 SCDS ears with those of 10 normal controls, found that the mean threshold in patients with SCDS was 101.2 \pm $5.5 \mathrm{~dB}$ pSPL compared with $116.7 \pm 4.7 \mathrm{~dB}$ pSPL for controls $(p<0.001)$, and all patients with SCDS had abnormally low threshold values. ${ }^{37}$

The second study, described earlier, found that using an oVEMP stimulus threshold value $<105 \mathrm{~dB}$
pSPL achieved a sensitivity of $100 \%(13 / 13)$ and specificity of $92 \%(14 / 15)$. When a threshold of $<99 \mathrm{~dB}$ pSPL as abnormal was applied, patients with SCDS were differentiated from controls with sensitivity of $76.9 \%(10 / 13)$ and specificity of $93.3 \%(14 / 15) .^{28}$

Conclusions. oVEMP amplitude possibly distinguishes SCDS from normal controls (3 Class III, 2 underpowered or inconclusive studies) with a sensitivity range of $77 \%-100 \%$ and a specificity range of $98 \%-100 \%$. The efficacy is unknown for use of a $4,000-\mathrm{Hz}$ stimulus to determine the presence or absence of an oVEMP response to differentiate ears with SCDS from normal ears (1 positive Class III study). An oVEMP threshold below a laboratoryspecific value (usually 2 SD below the mean threshold of controls) possibly distinguishes SCDS ears from normal ears with a sensitivity of $77 \%$ and a specificity of $93 \%$ (2 Class III studies).

Recommendation. oVEMP testing using either specific thresholds or amplitudes may be used in patients to aid in making an SCDS diagnosis (Level C). 
Figure 5 Ocular vestibular evoked myogenic potential (oVEMP) waveform in a healthy individual

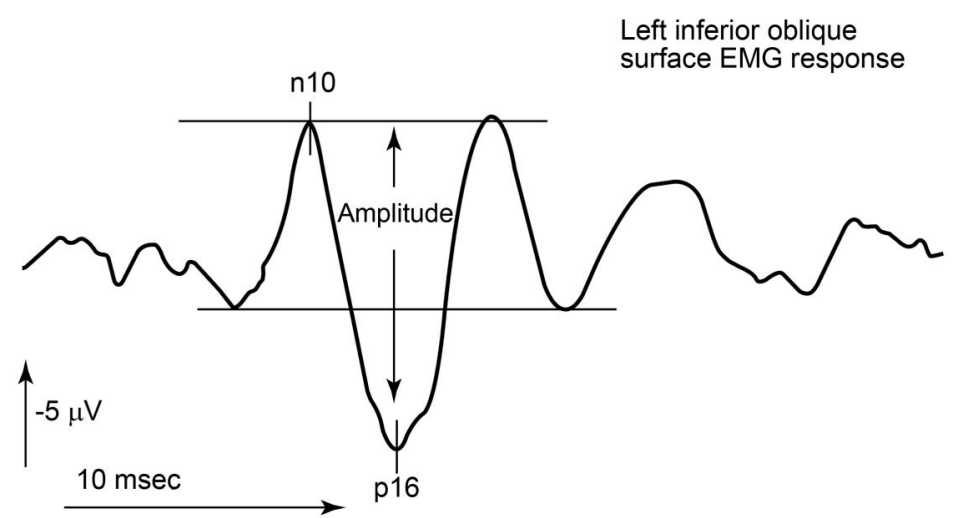

The recordings are from the surface EMG electrodes over the left inferior oblique in response to a sound stimulus in the right ear. The waveform shows the negative-positive oVEMP (n10-p16, sometimes simply referred to as $n 1$ and $\mathrm{p} 1$ ). Measurements include the latency, the amplitude, and the threshold (least intense sound stimulus to still yield a reliable response). The responses occur only on the side opposite the one receiving the sound stimulation. () Barrow Neurological Institute, Phoenix, AZ. Used with permission.

Clinical context for VEMP testing for SCDS. Both cVEMP and oVEMP in SCDS may show an abnormal response that is actually hyperactive. That is, SCDS requires a less intense sound stimulus than normal (i.e., lower threshold) to induce the response, and the response amplitude is abnormally increased on the affected side. No other vestibular disorder has yet demonstrated hyperactive VEMP responses to such a degree.

The false appearance of dehiscence by CT of the temporal bone can sometimes be seen in patients without SCDS. ${ }^{38-40}$ In some cases, a negative CT of the temporal bone but abnormal VEMP is due to dehiscence in a canal other than the superior canal. $^{24, e 1}$ To confirm SCDS, cVEMP and oVEMP provide a physiologic correlate to the clinical symptoms and the temporal bone CT findings. Hence, VEMP studies serve a complementary role in conjunction with temporal bone CT and clinical history in SCDS diagnosis. Normalization of VEMP amplitudes and thresholds after successful surgical repair of SCDS is further confirmation that VEMP studies correlate with the presence of a physiologically significant degree of dehiscence. ${ }^{33}$

For patients with suspected vestibular symptoms, does cVEMP/oVEMP accurately identify vestibular dysfunction related to the saccule/utricle? Because there is no reference standard test for isolated saccular/utricular loss, no method exists to directly determine in humans whether cVEMP responses reflect saccular function and whether oVEMP responses reflect utricular function. The guideline authors found studies correlating caloric vestibular loss with absence of oVEMP responses in vestibular neuritis (VN), but this only implies the relationship. Ultimately, this question was unanswerable using AAN guideline methodology.

Clinical context for cVEMP as a measure of saccular dysfunction and oVEMP as a measure of utricular dysfunction. Historically, animal studies have been essential in understanding the vestibular system. ${ }^{\mathrm{e} 2}$ For example, animal studies were a critical part of determining that caloric testing is a measure of horizontal semicircular canal function, which is now accepted. ${ }^{6, e 3}$ In the case of VEMP, animal studies suggest that cVEMP is most closely tied to function of the saccule and oVEMP to the utricle, although with some possible contribution from the semicircular canals. ${ }^{9,26,28, e 4, e 5}$

Conclusion. It is not known whether oVEMP/ cVEMP responses accurately identify vestibular function specifically related to the saccule/utricle (no relevant studies).

Recommendation. cVEMP and oVEMP have unknown efficacy in accurately identifying vestibular function specifically related to the saccule/utricle (Level U).

For patients with vestibular symptoms, does cVEMP/ oVEMP accurately and substantively aid diagnosis of any specific vestibular disorder besides SCDS? Vestibular neuritis. Class III studies have applied VEMP to VN. VEMP is viewed as helpful in identifying whether $\mathrm{VN}$ has led to dysfunction related to the superior or inferior (or both) branches of the vestibular nerve, ${ }^{\mathrm{e}-\mathrm{e} 9}$ supporting rather than making the diagnosis.

Clinical context. VN remains a clinical diagnosis with symptoms of acute vestibular dysfunction, normal hearing, and typical signs. ${ }^{\text {e10 }}$ Use of VEMP to parse out which parts of the nerve or labyrinth are affected is predicated on the notion that CVEMP is indicative of saccular function and oVEMP of utricular function. Although this notion is biologically plausible and supported by animal studies, and studies of $\mathrm{VN}$ have found that caloric loss correlates strongly with absence of oVEMP responses, direct evidence in humans of the type acceptable within the AAN guideline process is currently absent.

Conclusion. Expert consensus supports use of cVEMP and oVEMP to determine the extent of $\mathrm{VN}$ involvement, but with the methods used herein, no such determination can be made.

Recommendation. Evidence is insufficient to determine whether cVEMP/oVEMP use would clarify which vestibular structures are affected in $\mathrm{VN}$ (Level U).

Ménière disease. All 8 studies on Ménière disease are

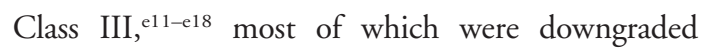
because of spectrum bias.

One study examined the ratio of oVEMP amplitudes at $500-\mathrm{Hz}$ and $750-\mathrm{Hz}$ sound stimulus. ${ }^{\text {e11 }}$ 
Comparing the amplitude ratio of $750 \mathrm{~Hz}$ to $500 \mathrm{~Hz}$ with cutoff of $>1.21$ yielded a sensitivity of $89 \%$ and a specificity of $100 \%$ when patients with Ménière disease were compared with controls.

Another study ${ }^{\mathrm{e} 7}$ showed no distinction of Ménière disease from controls for cVEMP/oVEMP.

Other Class III studies also examined cVEMP in Ménière disease. ${ }^{\text {e13-e18 }}$ None demonstrated an ability as a stand-alone diagnostic test to reliably diagnose Ménière disease. Some showed vestibular dysfunction manifesting as an ipsilaterally absent response.

Conclusion. On the basis of multiple conflicting or inconclusive studies, neither cVEMP nor oVEMP testing was found to be useful in diagnosing Ménière disease, but the studies possibly demonstrate that vestibular loss as assessed by VEMP may be seen in Ménière disease.

Recommendations. cVEMP may be used as an ancillary test in Ménière disease for vestibular dysfunction (Level C). There is insufficient evidence that either cVEMP or oVEMP may be used to diagnose Ménière disease (Level U).

Clinical context for using VEMP in Ménière disease. The diagnosis of Ménière disease has long been a clinical one, ${ }^{\mathrm{e} 19}$ and only recently has audiometry been added to the diagnostic criteria. ${ }^{20}$ There is no demonstrable role of VEMP in diagnosis of Ménière disease.

Benign paroxysmal positional vertigo. Two Class III studies ${ }^{\mathrm{e} 21, \mathrm{e} 22}$ examined cVEMP responses in patients with benign paroxysmal positional vertigo (BPPV) compared with those of healthy controls. Neither study found cVEMP to aid in establishing the BPPV diagnosis or to reliably distinguish patients with BPPV from controls.

Conclusion. cVEMP was not demonstrated to aid in establishing BPPV diagnosis (2 Class III studies).

Recommendation. cVEMP may not be used to make a BPPV diagnosis (Level C).

Clinical context for use of VEMP to diagnose BPPV. Diagnostic criteria for BPPV have been published. ${ }^{\mathrm{e} 23}$ No role for VEMP in the diagnosis of BPPV has been established.

Vestibular migraine. Three Class III studies addressed vestibular migraine (VM). ${ }^{\text {118,e2 } 4, e 25}$

The first study found absence of a cVEMP response in one or both ears in $44 \%(16 / 37)$ of patients with VM and in 3\% (1/30) of controls, yielding a sensitivity of $43 \%(95 \%$ CI $27.5 \%-60.3 \%)$ and a specificity of $97 \%(95 \%$ CI $80.9 \%-99.8 \%){ }^{\text {e } 24}$

The second study used cVEMP measurements and found a sensitivity of $31 \%$ using absence of a response as an indicator of VM. ${ }^{18}$ This lack of response, however, is not diagnostic of VM, and the study authors made no assertion that cVEMP is helpful in distinguishing patients with VM from controls.
The third study found more absent oVEMP or asymmetric oVEMP amplitude responses in $39 \mathrm{pa}-$ tients with VM than in 29 controls; however, cVEMP responses were not statistically different between the 2 groups. ${ }^{\text {e25 }}$

Conclusion. In patients with VM, it is possible an absent VEMP response or asymmetric amplitude is more common than in controls, but in no study was VEMP useful in establishing a VM diagnosis.

Recommendation. Although an absent VEMP response in one or both ears appears to occur more often in patients with VM than in normal controls, VEMP may not be used to assist in VM diagnosis or management (Level C).

Clinical context for using VEMP in VM. VM is a clinical diagnosis with established clinical criteria. ${ }^{e 26}$ No vestibular test makes the diagnosis of VM, but vestibular tests, including VEMP, may clarify the status of vestibular function when needed to exclude other conditions.

Other vestibular conditions. The guideline panel found insufficient data to determine the usefulness of VEMP in diagnosing other vestibular disorders.

Conclusion/recommendation. Data are insufficient to make recommendations regarding use of VEMP in diagnosis of other specific vestibular disorders besides SCDS (Level U).

\section{RECOMMENDATIONS FOR FUTURE RESEARCH}

More standardization is needed of stimulation and recording methods, and of normal and pathologic ranges of the amplitudes and latencies, with specifications of the reporting measures, if cVEMP and oVEMP are to be used more effectively in clinical practice. ${ }^{16,227}$ This also requires that each laboratory determine its own normal and pathologic ranges for each test for younger and older patients. Quality studies with low risk of bias are needed to better inform the role of VEMP in clinical evaluation of various otologic and neurologic disorders. Human studies are needed to confirm that cVEMP and oVEMP are indicative predominantly of saccular and utricular function, respectively.

DISCLAIMER Clinical practice guidelines, practice advisories, systematic reviews, and other guidance published by the American Academy of Neurology and its affiliates are assessments of current scientific and clinical information provided as an educational service. The information (1) should not be considered inclusive of all proper treatments, methods of care, or as a statement of the standard of care; (2) is not continually updated and may not reflect the most recent evidence (new evidence may emerge between the time information is developed and when it is published or read); (3) addresses only the question(s) 
specifically identified; (4) does not mandate any particular course of medical care; and (5) is not intended to substitute for the independent professional judgment of the treating provider, as the information does not account for individual variation among patients. In all cases, the selected course of action should be considered by the treating provider in the context of treating the individual patient. Use of the information is voluntary. AAN provides this information on an "as is" basis, and makes no warranty, expressed or implied, regarding the information. AAN specifically disclaims any warranties of merchantability or fitness for a particular use or purpose. AAN assumes no responsibility for any injury or damage to persons or property arising out of or related to any use of this information or for any errors or omissions.

CONFLICT OF INTEREST The American Academy of Neurology is committed to producing independent, critical, and truthful practice guidelines. Significant efforts are made to minimize the potential for conflicts of interest to influence the recommendations of this practice guideline. To the extent possible, the AAN keeps separate those who have a financial stake in the success or failure of the products appraised in the practice guidelines and the developers of the guidelines. Conflict of interest forms were obtained from all authors and reviewed by an oversight committee prior to project initiation. AAN limits the participation of authors with substantial conflicts of interest. The AAN forbids commercial participation in, or funding of, guideline projects. Drafts of the guideline have been reviewed by at least 3 AAN committees, a network of neurologists, Neurology peer reviewers, and representatives from related fields. The AAN Guideline Author Conflict of Interest Policy can be viewed at aan.com. For complete information on this process, access the 2004 AAN process manual. ${ }^{27}$

\section{AUTHOR CONTRIBUTIONS}

Dr. Fife: study concept and design, acquisition of data, analysis or interpretation of data, drafting/revising the manuscript, critical revision of the manuscript for important intellectual content, study supervision. Dr. Colebatch: study concept and design, acquisition of data, analysis or interpretation of data, drafting/revising the manuscript, critical revision of the manuscript for important intellectual content. Dr. Kerber: analysis or interpretation of data, drafting/revising the manuscript, critical revision of the manuscript for important intellectual content. Dr. Brantberg: analysis or interpretation of data. Dr. Strupp: analysis or interpretation of data, drafting/revising the manuscript. Dr. Lee: analysis or interpretation of data. Dr. Walker: analysis or interpretation of data. Dr. Ashman: analysis or interpretation of data. Dr. Fletcher: analysis or interpretation of data. Dr. Callaghan: analysis or interpretation of data. Dr. Gloss: analysis or interpretation of data, drafting/revising the manuscript, critical revision of the manuscript for important intellectual content, study supervision.

\section{STUDY FUNDING}

This practice guideline was developed with financial support from the American Academy of Neurology. Authors who serve or served as
AAN subcommittee members or methodologists (T.D.F., E.A., J.F., B.C., D.S.G.) were reimbursed by the AAN for expenses related to travel to subcommittee meetings where drafts of manuscripts were reviewed.

\section{DISCLOSURE}

T. Fife and J. Colebatch report no disclosures relevant to the manuscript. K. Kerber has received travel support from GN Otometrics and serves as editor of the Neurology ${ }^{\circledR}$ Innovations in Care Delivery. K. Brantberg reports no disclosures relevant to the manuscript. M. Strupp serves as Joint Chief-Editor of the Journal of Neurology, as Editor-in-Chief of Frontiers in Neuro-otology, and as Section Editor of F1000; has received support in the form of a German Federal Ministry of Education and Research grant (No. 01EO0901) to the German Dizziness Center (Integrated Center for Research and Treatment of Vertigo, Balance and Ocular Disorders); has received speakers honoraria from Abbott, Actelion, Biogen, Eisai, GlaxoSmithKline, Henning Pharma, Interacoustics, Merck Sharp \& Dohme, Otometrics, Pierre-Fabre, Teva, and UCB; and acts as a consultant for Abbott, Actelion, Auris Medical, Heel, IntraBio, and Sensorion. H. Lee, M. Walker, E. Ashman, and J. Fletcher report no disclosures relevant to the manuscript. B. Callaghan received grant funding from the Patient-Centered Outcomes Research Institute through the Kaiser Permanente group and received financial or material research support from Impeto Medical and the NIH (K23 Mentored PatientOriented Research Career Development Award). D. Gloss reports no disclosures relevant to the manuscript. Go to Neurology.org for full disclosures.

Received May 12, 2017. Accepted in final form August 22, 2017.

\section{REFERENCES}

1. Colebatch JG, Halmagyi GM. Vestibular evoked potentials in human neck muscles before and after unilateral vestibular differentiation. Neurology 1992;42:1635-1636.

2. Colebatch JG, Halmagyi GM, Skuse NF. Myogenic potentials generated by a click-evoked vestibulocollic reflex. J Neurol Neurosurg Psychiatry 1994;57:190-197.

3. Clarke AH. Laboratory testing of the vestibular system. Curr Opin Otolaryngol Head Neck Surg 2010;18:425-430.

4. Magliulo G, Gagliardi S, Appiani MC, Iannella G, Re M. Vestibular neurolabyrinthitis: a follow-up study with cervical and ocular vestibular evoked myogenic potentials and the video head impulse test. Ann Otol Rhinol Laryngol 2014;123:162-173.

5. Murofushi T. Clinical application of vestibular evoked myogenic potentials (VEMP). Auris Nasus Larynx 2016; 43:367-376.

6. Curthoys IS. The interpretation of clinical tests of peripheral vestibular function. Laryngoscope 2012;122:1342-1352.

7. Dennis DL, Govender S, Colebatch JG. Properties of cervical and ocular vestibular evoked myogenic potentials (cVEMPs and oVEMPs) evoked by $500 \mathrm{~Hz}$ and $100 \mathrm{~Hz}$ bone vibration at the mastoid. Clin Neurophysiol 2015; 127:848-857.

8. Kushiro K, Zakir M, Ogawa Y, Sato H, Uchino Y. Saccular and utricular inputs to SCM motoneurons of decerebrate cats. Exp Brain Res 1999;126:410-416.

9. Curthoys IS. A critical review of the neurophysiological evidence underlying clinical vestibular testing using sound, vibration and galvanic stimuli. Clin Neurophysiol 2010; 121:132-144.

10. Colebatch JG, Rothwell JC. Motor unit excitability changes mediating vestibulocollic reflexes in the sternocleidomastoid muscle. Clin Neurophysiol 2004;115: 2567-2573.

11. Brooke RE, Herbert NC, Thyer NJ. Repeatability of sound-evoked triceps myogenic potentials. Int J Audiol 2014;53:880-886. 
12. Rudisill H, Hain TC. Lower extremity myogenic potentials evoked by acoustic stimuli in healthy adults. Otol Neurotol 2008;29:688-692.

13. Manzari L, Burgess AM, Curthoys IS. Ocular and cervical vestibular evoked myogenic potentials in response to boneconducted vibration in patients with probable inferior vestibular neuritis. J Laryngol Otol 2012;15:1-9.

14. Curthoys IS, Kim J, McPhedran SK, Camp AJ. Bone conducted vibration selectively activates irregular primary otolithic vestibular neurons in the guinea pig. Exp Brain Res 2006;175:256-267.

15. Papathanasiou ES, Murofushi T, Akin FW, Colebatch JG. International guidelines for the clinical application of cervical vestibular evoked myogenic potentials: an expert consensus report. Clin Neurophysiol 2014;125:658-666.

16. Welgampola MS, Colebatch JG. Vestibulocollic reflexes: normal values and the effects of age. Clin Neurophysiol 2001;112:1971-1979.

17. Rosengren SM, Govender S, Colebatch JG. Ocular and cervical vestibular evoked myogenic potentials produced by air- and bone-conducted stimuli: comparative properties and effects of age. Clin Neurophysiol 2011;122: 2282-2289.

18. Murofushi T. Vestibular evoked myogenic potential. World J Otorhinolaryngol 2014;4:6-11.

19. Minor LB, Carey JP, Cremer PD, Lustig LR, Streubel SO, Ruckenstein MJ. Dehiscence of bone overlying the superior canal as a cause of apparent conductive hearing loss. Otol Neurotol 2003;24:270-278.

20. Carey JP, Minor LB, Nager GT. Dehiscence or thinning of bone overlying the superior semicircular canal in a temporal bone survey. Arch Otolaryngol Head Neck Surg 2000;126:137-147.

21. Davey S, Kelly-Mortland C, Phillips JS, Nunney I, Pawaroo D. Assessment of superior semicircular canal thickness with advancing age. Laryngoscope 2015;125:1940-1945.

22. Chien WW, Janky K, Minor LB, Carey JP. Superior canal dehiscence size: multivariate assessment of clinical impact. Otol Neurotol 2012;33:810-815.

23. Shaia WT, Diaz RC. Evolution in surgical management of superior canal dehiscence syndrome. Curr Opin Otolaryngol Head Neck Surg 2013;21:497-502.

24. Zhou G, Gopen Q, Poe DS. Clinical and diagnostic characterization of canal dehiscence syndrome: a great otologic mimicker. Otol Neurotol 2007;28:920-926.

25. Zuniga MG, Janky KL, Nguyen KD, Welgampola MS, Carey JP. Ocular versus cervical VEMPs in the diagnosis of superior semicircular canal dehiscence syndrome. Otol Neurotol 2012;34:121-126.

26. Fife TD, Tusa RJ, Furman JM, et al. Assessment: vestibular testing techniques in adults and children. Report of the Therapeutics and Technology Assessment Subcommittee of the American Academy of Neurology. Neurology 2000;55:1431-1441.

27. Edlund W, Gronseth G, So Y, Franklin G. Clinical Practice Guideline Process Manual, 2004 ed: American Academy of Neurology; 2004. Available at: aan.com/uploadedFiles/
Website_Library_Assets/Documents/2.Clinical_Guidelines/ 4.About_Guidelines/1.How_Guidelines_Are_Developed/ 2004\%20AAN\%20Process\%20Manual.pdf. Accessed September 12, 2012.

28. Govender S, Fernando T, Dennis DL, Welgampola MS, Colebatch JG. Properties of $500 \mathrm{~Hz}$ air- and boneconducted vestibular evoked myogenic potentials (VEMPs) in superior canal dehiscence. Clin Neurophysiol 2016;127:2522-2531.

29. Janky KL, Nguyen KD, Welgampola M, Zuniga MG, Carey JP. Air-conducted oVEMPs provide the best separation between intact and superior canal dehiscent labyrinths. Otol Neurotol 2012;34:127-134.

30. Roditi RE, Eppsteiner RW, Sauter TB, Lee DJ. Cervical vestibular evoked myogenic potentials (cVEMPs) in patients with superior canal dehiscence syndrome (SCDS). Otolaryngol Head Neck Surg 2009;141:24-28.

31. Wackym PA, Ratigan JA, Birck JD, et al. Rapid cVEMP and oVEMP responses elicited by a novel head striker and recording device. Otol Neurotol 2012;33:1392-1400.

32. Brantberg K, Verrecchia L. Testing vestibular-evoked myogenic potentials with $90-\mathrm{dB}$ clicks is effective in the diagnosis of superior canal dehiscence syndrome. Audiol Neurotol 2009;14:54-58.

33. Welgampola MS, Myrie OA, Minor LB, Carey JP. Vestibular-evoked myogenic potential thresholds normalize on plugging superior canal dehiscence. Neurology 2008;70: 464-472.

34. Taylor RL, Bradshaw AP, Halmagyi GM, Welgampola MS. Tuning characteristics of ocular and cervical vestibular evoked myogenic potentials in intact and dehiscent ears. Audiol Neurol 2012;17:207-218.

35. Thabet EM, Abdelkhalek A, Zaghloul H. Superior semicircular canal dehiscence syndrome as assessed by oVEMP and temporal bone computed tomography imaging. Eur Arch Otorhinolaryngol 2012;269:1545-1549.

36. Manzari L, Burgess AM, McGarvie LA, Curthoys IS. An indicator of probable semicircular canal dehiscence: ocular vestibular evoked myogenic potentials to high frequencies. Otol Neurotol 2013;149:142-145.

37. Rosengren SM, Aw ST, Halmagyi GM, et al. Ocular vestibular evoked myogenic potentials in superior canal dehiscence. J Neurol Neurosurg Psychiatry 2008;79:559-566.

38. Mikulec AA, McKenna MJ, Ramsey MJ, et al. Superior semicircular canal dehiscence presenting as conductive hearing loss without vertigo. Otol Neurotol 2004;25: 121-129.

39. Masaki Y. The prevalence of superior canal dehiscence syndrome as assessed by temporal bone computerized tomography imaging. Acta Otolaryngol 2011;131: 258-262.

40. Sandhu JS, Manickavasagam J, Connolly D, Raghavan A, Fernando M, Ray J. Comparison of radiographically and histologically determined thickness of the bone overlying the superior semicircular canal in sixty-six cadaveric specimens: impact on the diagnosis of Minor's syndrome. Clin Otolaryngol 2017;42:847-850. 


\section{Neurology}

Practice guideline: Cervical and ocular vestibular evoked myogenic potential testing:

Report of the Guideline Development, Dissemination, and Implementation

Subcommittee of the American Academy of Neurology

Terry D. Fife, James G. Colebatch, Kevin A. Kerber, et al.

Neurology 2017;89;2288-2296 Published Online before print November 1, 2017

DOI 10.1212/WNL.0000000000004690

This information is current as of November 1, 2017

\section{Updated Information \&} Services

Supplementary Material

\section{References}

Citations

Subspecialty Collections

Permissions \& Licensing

Reprints including high resolution figures, can be found at: http://n.neurology.org/content/89/22/2288.full

Supplementary material can be found at: http://n.neurology.org/content/suppl/2017/11/01/WNL.0000000000004 690.DC1

This article cites 39 articles, 5 of which you can access for free at: http://n.neurology.org/content/89/22/2288.full\#ref-list-1

This article has been cited by 1 HighWire-hosted articles: http://n.neurology.org/content/89/22/2288.full\#\#otherarticles

This article, along with others on similar topics, appears in the following collection(s):

All Neurotology

http://n.neurology.org/cgi/collection/all_neurotology

Evoked Potentials/Auditory

http://n.neurology.org/cgi/collection/evoked_potentials-auditory

Evoked Potentials/Visual

http://n.neurology.org/cgi/collection/evoked_potentials-visual

Information about reproducing this article in parts (figures,tables) or in its entirety can be found online at:

http://www.neurology.org/about/about_the_journal\#permissions

Information about ordering reprints can be found online:

http://n.neurology.org/subscribers/advertise

Neurology ${ }^{\circledR}$ is the official journal of the American Academy of Neurology. Published continuously since 1951, it is now a weekly with 48 issues per year. Copyright @ 2017 American Academy of Neurology. All rights reserved. Print ISSN: 0028-3878. Online ISSN: 1526-632X.

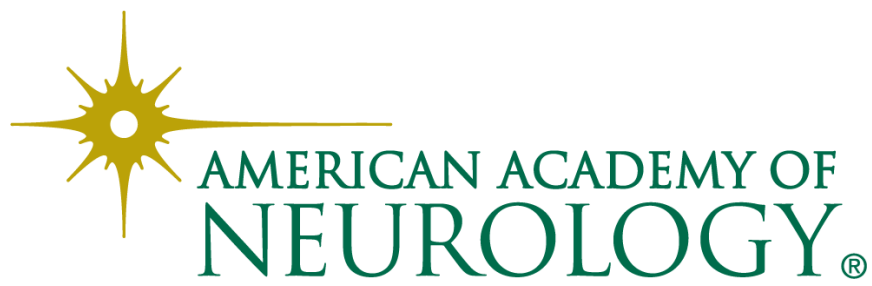

